\title{
Enhanced stability of phenylethyl resorcinol in elastic vesicular formulations
}

\author{
Tunyaluk Limsuwan ${ }^{1}$, Prapaporn Boonme ${ }^{1,2}$, Thanaporn Amnuaikit ${ }^{1 *}$ \\ ${ }^{1}$ Department of Pharmaceutical Technology, Faculty of Pharmaceutical Sciences, Prince of Songkla University, ${ }^{2}$ Nanotec-PSU \\ Center of Excellence on Drug Delivery System, Songkhla 90112, Thailand
}

*For correspondence: Email: chomchan.a@psu.ac.th; Tel: +6674288849

Sent for review: 4 May 2018

Revised accepted: 19 September 2018

\begin{abstract}
Purpose: To enhance the stability and reduce photo-degradation of phenylethyl resorcinol (PR) by elastic vesicle formation.

Methods: PR solution was stored at different temperatures, $\mathrm{pH}$ conditions, and under protected and unprotected natural light. The color of the solution and total active content were investigated. Three types of elastic vesicles, viz, ethosomes, transfersomes and invasomes, were prepared and their sedimentation in formulations and total active content were investigated before and after storage under various conditions for 4 months. The stability of the solutions and vesicular formulations were assessed. Results: PR solution was unstable at $p H 9$, higher temperature $\left(70 \pm 1^{\circ} \mathrm{C}\right)$ and under natural light. The color of $P R$ solution changed from colorless to orange tone and the PR content decreased. On the other hand, PR entrapped within ethosome, tranfersome and invasome vesicles showed better stability, color change was not observed in the formulations, and PR content remained $>90 \%$.

Conclusion: All the vesicles display reduced degradation of $P R$ under thermal and natural light. Thus, $P R$ vesicular formulation enhances stability and improves the quality of the product for use in topical administration.
\end{abstract}

Keywords: Phenylethyl resorcinol, Degradation, Ethosomes, Transfersomes, Invasomes, Topical administration

\begin{abstract}
This is an Open Access article that uses a funding model which does not charge readers or their institutions for access and distributed under the terms of the Creative Commons Attribution License (http://creativecommons.org/licenses/by/4.0) and the Budapest Open Access Initiative (http://www.budapestopenaccessinitiative.org/read), which permit unrestricted use, distribution, and reproduction in any medium, provided the original work is properly credited.
\end{abstract}

Tropical Journal of Pharmaceutical Research is indexed by Science Citation Index (SciSearch), Scopus, International Pharmaceutical Abstract, Chemical Abstracts, Embase, Index Copernicus, EBSCO, African Index Medicus, JournalSeek, Journal Citation Reports/Science Edition, Directory of Open Access Journals (DOAJ), African Journal Online, Bioline International, Open-J-Gate and Pharmacy Abstracts

\section{INTRODUCTION}

Phenylethyl Resorcinol (4 - (1- Phenylethyl) 1, 3Benzenediol, PR) is a recently introduced skinlightening agent that can interrupt tyrosinase activity by obstructing tyrosine being converted to L-3,4-dihydroxyphenylalanine (L-DOPA) [1]. The previous research reported that PR has more effective tyrosinase inhibition compared to kojic acid, both in vitro epidermal model
(MelanoDermaTM) and in vitro mushroom tyrosinase, approximately 22 times more [2]. In addition, it served as an antioxidant, which is more effective than butylated hydroxytoluene $(\mathrm{BHT})$, ascorbic acid (vitamin C), and alpha tocopherol (vitamin E) [3]. Moreover, recently it has also shown a significantly higher antifungal activity than the antifungal agent fluconazole [4]. Nevertheless, the formulation of PR as topical products is limited because of the poor water 
solubility and instability in light which leads to the decrease in effectiveness when used [5].

Several researches reported that the stability and solubility of the active ingredient improved by nano-encapsulation techniques. According to the previous researches, the vesicle carriers were studied; for example, liposome and nanostructure lipid carrier (NLC). The PR showed stability for at least 90 days when encapsulated within liposome [6]. In addition, after loading the PR into NLC, it was found that there was excellent physiochemical stability under day light over 3 months [7]. These researches supported that the photo-stability and solubility of the vesicle carriers can be increased by protection of encapsulated actives from the external environment. It was reported that the elastic vesicles not only improved solubility and photo-stability, but also improved permeation of active ingredients through/to the skin [8-11]. Therefore, in this study, elastic vesicle carriers such as PR-loaded ethosomes, transfersomes and invasomes were assessed for overcoming the limitation of using PR for topical products.

\section{EXPERIMENTAL}

\section{Materials}

PR was obtained from Starchem Enterprises Limited (Nanjing, China). L- $\alpha$ phosphatidylcholine from soybean (SPC) and cholesterol (CHOL) were obtained from SigmaAldrich (Missouri, USA). Absolute ethanol was obtained from $\mathrm{RCl}$ Labscan Limited (Bangkok, Thailand). (R)-(+)-Limonene and (1R)-(-)Fenchone were obtained from Sigma-Aldrich (WGK, Germany). Sodium deoxycholate (SDC) were obtained from Homedia ${ }^{\circledR}$ (Mumbai, India). Milli-Q water was prepared by Faculty of Pharmaceutical Sciences, PSU. None of the chemicals obtained were modified, and they were all used in the same state as they were received.

\section{Solubility study of PR}

Since the solubility property influences the preparation of vesicle formulation, the effects that ethanol and $\mathrm{pH}$ concentrations can have on PR solubility were evaluated. The effect of ethanol concentrations on PR solubility was studied to discover the suitable dispersion medium for preparing the ethosomes containing PR. The solubility of $\mathrm{PR}$ in ethanol : water mixed at various ethanol concentrations was determined. This study was carried out by adding an additional amount of PR into glass vials containing $5 \mathrm{ml}$ of various ethanol concentrations
$(0,10,20,30,40,50,80$, and $100 \% \mathrm{v} / \mathrm{v}$ in water). These samples were then sonicated for 30 minutes and preserved at room temperature $\left(30 \pm 1^{\circ} \mathrm{C}\right)$. After 48 and 72 hours, samples were tested to determine if the solubility of PR has reached equilibrium. Solutions which were saturated were filtered by a $0.45 \mu \mathrm{m}$ syringe filter membrane, then diluted with methanol, and finally analyzed for PR content at $254 \mathrm{~nm}$ using high-performance liquid chromatography (HPLC). These experiments were reciprocated for 3 times, and all the samples were examined in triplicate.

The effect of $\mathrm{pH}$ conditions on PR solubility was evaluated to find out the suitable receptor medium system in skin permeation study. The effect of $\mathrm{pH}$ on PR solubility was studied at four different $\mathrm{pHs}$ (2.0, 5.5, 7.4 and 9.0). An excess amount of PR was added in glass vials holding 5 $\mathrm{ml}$ hydrochloric acid buffer having $\mathrm{pH} 2.0$, acetate buffer having $\mathrm{pH} 5.5$, and phosphate buffer having $\mathrm{pH} 7.4$ and 9.0 which was prepared in consonance with USP 30 [12]. These samples were first sonicated for 30 minutes, then preserved at room temperature $\left(30 \pm 1^{\circ} \mathrm{C}\right)$ for 48 and 72 hours to determine if the solubility of PR has reached equilibrium. Solutions which were saturated were filtered by a $0.45 \mu \mathrm{m}$ syringe filter membrane. Afterwards methanol was used to dilute them, before determining the PR content using HPLC at $254 \mathrm{~nm}$. These experiments were reciprocated for 3 times, and all the samples were examined in triplicate.

\section{Degradation study of PR}

The stability and degradability of PR under various $\mathrm{pH}$, temperature, and light conditions were studied following the method explained by Ding et al [13]. The thermal stability of PR was studied at 4, 30, 45 and $70{ }^{\circ} \mathrm{C}$ under controlled humidity at $75 \% \mathrm{RH} .50 \mathrm{mg}$ of PR was dissolved in $250 \mathrm{ml}$ of phosphate buffer having $\mathrm{pH} 7.0$ to prepare the sample solution with a final concentration of $200 \mu \mathrm{g} / \mathrm{ml}$. A $20 \mathrm{ml}$ of sample solution was displaced into test tubes, capped to avoid evaporation and covered with aluminum foil to protect from light. Test tubes were kept in a refrigerator at $4 \pm 1{ }^{\circ} \mathrm{C}$, stored at $30 \pm 1{ }^{\circ} \mathrm{C}, 45 \pm$ $1{ }^{\circ} \mathrm{C}$ and $70 \pm 1{ }^{\circ} \mathrm{C}$ inside a Constant Climate Chamber (Model HPP260, Memmert, Schwabach, Germany), respectively. At the temperature $4, \quad 30$ and $45{ }^{\circ} \mathrm{C}, 500 \mu \mathrm{l}$ of supernatant was withdrawn to determine the content of PR at $0,0.5,1,5,9,12,24$ and 30 days. At the temperature of $70{ }^{\circ} \mathrm{C}$, the content of PR was studied at $0,3,6,9,12,15,24$ and 30 hours. The supernatant was filtered using a 0.45 $\mu \mathrm{m}$ syringe filter membrane and was examined 
using HPLC at $254 \mathrm{~nm}$. These experiments were reciprocated for 3 times, and all the samples were examined in triplicate.

The effect of $\mathrm{pH}$ on PR stability was studied at four different $\mathrm{pHs}(2.0,5.5,7.4$ and 9.0) at the room temperature $\left(30 \pm 1{ }^{\circ} \mathrm{C}\right)$. An accurate concentration of PR $(200 \mu \mathrm{g} / \mathrm{ml})$ in different $\mathrm{pHs}$ was prepared. Each buffer solution was transferred equally into three test tubes. Then, it was capped tightly to avoid evaporation and covered by aluminum foil to protect from light. $500 \mu \mathrm{l}$ of sample was removed at $0,0.5,1,3,5$, 7,14 , and 30 days to determine the content of PR using HPLC. These experiments were reciprocated for 3 times, and all the samples were examined in triplicate.

The effect of light on PR was studied to evaluate the photo-stability. $200 \mu \mathrm{g} / \mathrm{ml}$ of PR in phosphate buffer $\mathrm{pH} 7.0$ was prepared and a $20 \mathrm{ml}$ sample was transferred into test tube. After that, it was capped tightly to avoid evaporation and stored in room temperature under light protection by covering with aluminum foil and under natural light. On study day $0,0.5,1,3,5,7,14$ and 30 days, the $500 \mu$ l of sample was collected, filtered using a $0.45 \mu \mathrm{m}$ syringe filter membrane and analyzed using HPLC to determine the concentration of PR. These experiments were reciprocated for 3 times, and all the samples were examined in triplicate.

\section{Kinetic analysis}

The concentration of PR remaining was calculated and expressed in mean \pm standard error. Degradation rate kinetics was determined by plotting concentration versus time (zero-order reaction), logarithm of concentration versus time (first-order reaction) and concentration ${ }^{-1}$ versus time (second-order reaction). The correlation coefficients $\left(r^{2}\right)$ were calculated and the best fit for indicating the reaction order was determined. The kinetics models can be represented as in Eqs 1 - 3 [14]:

Zero-order reaction:

$$
\begin{gathered}
C=C_{0}-k t \\
t_{1 / 2}=C_{0} / 2 k
\end{gathered}
$$

First-order reaction:

$\ln C=\ln C_{0}-k t$

$t_{1 / 2}=\ln 2 / k$

Second-order reaction:
$1 / C=1 / C_{0}+k t$

$t_{1 / 2}=1 / k C_{0}$

where $C_{0}=$ the concentration of the reactants under consideration at time zero, $C$ the concentration after reaction time $(\mathrm{t})$ and $k$ the reaction rate constant.

\section{Preparation of vesicular formulations}

In this study, the ethosomes, transfersomes and invasomes were selected to study on improving stability of PR. All vesicles were prepared accounting to the method of our previous reports [15-17]. The main composition of all vesicles composed of $3 \% \mathrm{w} / \mathrm{v}$ SPC: $0.5 \% \mathrm{w} / \mathrm{v}$ CHOL: 0.5 $\%$ w/v PR: up to $100 \% \mathrm{v} / \mathrm{v}$ water phase. The penetration enhancer absolute ethanol, SDC and D-limonene mixed with $10 \% \mathrm{v} / \mathrm{v}$ absolute ethanol were added into the main composition for ethosomes, transfersomes and invasomes, respectively. Thin film hydration method was used to prepare these compositions. Finally, the physical property and total active content were evaluated at initial time and after storing at $4 \pm 1$, $30 \pm 1$ and $45 \pm 1{ }^{\circ} \mathrm{C}$ at $75 \% \mathrm{RH}$ in a Constant Climate Chamber (Model HPP260, Memmert, Schwabach, Germany) for 4 months. In addition, all formulations were prepared for the morphology study according to the method explained by Limsuwan et al and Amnuaikit et al $[16,17]$. The surface morphology and the structure within the vesicles were observed by scanning electron microscopy (SEM, Quanta 400, FEl, Czech Republic) and transmission electron microscopy (TEM, JEM-2010, JEOL, Japan), respectively.

\section{Quantitative determination of PR}

The quantitative determination of $P R$ in all experiments was carried out using HPLC method which was followed by Limsuwan et al [18]. Analysis was done using Agilent 1100 series with a BDS HYPERSIL C18 column (150 x $4.6 \mathrm{~mm}, 5$ $\mu \mathrm{m})$ at $25^{\circ} \mathrm{C}$ was used for analysis. The mixture of acetonitrile, methanol, milli-Q water as $40: 20: 40 \% \mathrm{v} / \mathrm{v} / \mathrm{v}$ was used as mobile phase, maintained at $0.8 \mathrm{ml} / \mathrm{min}$. Then, sample solution of $20 \mu \mathrm{l}$ was injected, and quantity of the PR was detected at $254 \mathrm{~nm}$.

\section{Statistical analysis}

The data collected from this study were presented as mean \pm standard deviation (SD). Student t-test or one-way analysis of variance (ANOVA) followed by post hoc analysis was used to test the statistical significant of 
differences between or among groups. The statistically significant value was considered at $P$ $<0.05$.

\section{RESULTS}

\section{Ethanol-solubility profile}

The effect of ethanol concentrations on PR solubility were studied, the results were expressed as ethanol-solubility profile in Figure 1 A. PR exhibited that it was slightly soluble in water $\left(318.83 \pm 22.02 \mu \mathrm{g} / \mathrm{ml}\right.$ at $25^{\circ} \mathrm{C}$ for $\left.72 \mathrm{~h}\right)$ which is similar to the previous report of PR solubility $\left(265 \mu \mathrm{g} / \mathrm{ml}\right.$ at $\left.25^{\circ} \mathrm{C}\right)$ [15].

\section{pH-solubility profile}

$\mathrm{pH}$-solubility profile (Figure $1 \mathrm{~B}$ ) showed that the solubility of $\mathrm{PR}$ in acidic range was higher than alkaline range. The solubility $\mathrm{PR}$ in $\mathrm{pH} 1.5$ and $\mathrm{pH} 2.0$ were higher than the solubility $\mathrm{PR}$ in $\mathrm{pH}$ 7.4 and $\mathrm{pH}$ 8.0. These results indicated that the PR solubility decreased when the $\mathrm{pH}$ increased.
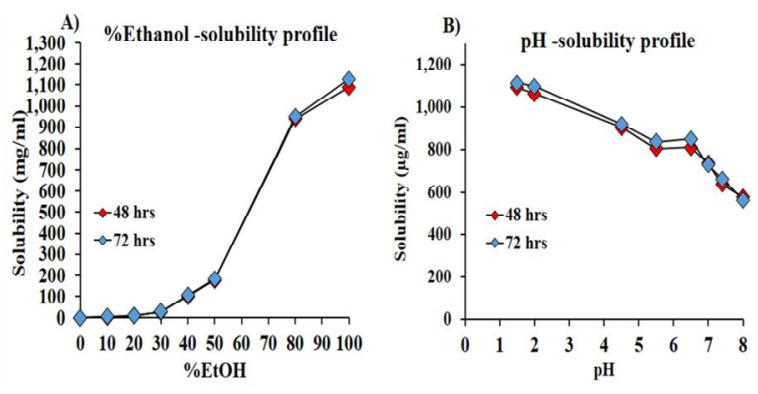

Figure 1: The ethanol $(\mathrm{A})$ and $\mathrm{pH}$-solubility profile $(\mathrm{B})$ of $\mathrm{PR}$ at room temperature $\left(30 \pm 1^{\circ} \mathrm{C}\right)$ for 48 and 72 hours. Each value represents the mean $\pm \operatorname{SD}(n=3)$

\section{Effect of temperature on PR}

Figure $2 \mathrm{~A}-\mathrm{D}$ shows $\mathrm{PR}$ concentration after storing at $4 \pm 1,30 \pm 1,45 \pm 1{ }^{\circ} \mathrm{C}$ and $70 \pm 1{ }^{\circ} \mathrm{C}$ under controlled humidity at $75 \% \mathrm{RH}$. After the samples were kept at $4 \pm 1,30 \pm 1,45 \pm 1{ }^{\circ} \mathrm{C}$ for 30 days, the physical property and PR concentration remained unchanged. Whereas, after storing the sample at $70 \pm 1{ }^{\circ} \mathrm{C}$ for 30 hours, the PR concentration decreased from $183.96 \pm 0.38$ to $164.78 \pm 5.5 \mu \mathrm{g} / \mathrm{ml}$.

\section{Effect of pH on PR}

The effect of four different $\mathrm{pH}$ values $(2.0,5.5$, 7.4 and 9.0) on PR stability studied at the room temperature $\left(30 \pm 1^{\circ} \mathrm{C}\right)$ are shown in Figure $2 \mathrm{E}$ $\mathrm{H}$. The PR concentration in $\mathrm{pH} 2.0,5.5,7.4$ demonstrated that it slightly decreased after storing for 30 days; on the other hand, the PR concentration in $\mathrm{pH} 9.0$ highly decreased. At pH
9.0, the PR concentration decreased from 93.48 \pm 1.16 to $73.48 \pm 3.61 \%$. Therefore, $\mathrm{PR}$ is stable in $\mathrm{pH}$ ranging from 2-7.4, whereas it is not stable at $\mathrm{pH} 9$.

\section{Effect of natural light on PR}

Figure 2 shows the PR concentration after storing under natural light (Figure $2 \mathrm{I}$ ) and under light protection (Figure $2 \mathrm{~J}$ ). It was stable under light protection because there was no change in the PR concentration and the color of PR solution (Figure 3, LP1 - LP3). In contrary, when the PR solution was kept under natural light, the PR content was decreased. The PR concentration at initial time was $93.13 \pm 0.31 \%$ while the PR concentration under natural light at 30 days was $54.80 \pm 8.75 \%$ (Figure $2 \mathrm{I}$ ). In addition, the color of PR solution after storing for 30 days changed to orange color as shown in Figure 3, NL1 - NL3. Our results clarified that the PR solution was not stable under light condition. This is a problem when it comes to formulation of PR cosmetic and skin dermal products. Therefore, overcoming the limitation of using PR as topical product by increasing the light stability is necessary. In this study of nanoencapsulation techniques; ethosomes, transfersomes and invasomes were selected to increase light stability of PR. These systems were not only protecting the encapsulated actives from external environment, but also improving the skin permeation of PR through/to the skin.

\section{The kinetic study}

After collecting the data, the linear regression was plotted between time point's and stability test results following each kinetic model.

The slope of the regression equation was evaluated to confirm the goodness of fit of the linear regression. If the $p$-value of slope is larger than or equals to 0.05 that means the slope of regression equation equals to zero. It represents that there is no change in stability test results under the studied conditions. In addition, $r^{2}$ value was calculated which was near to 1 , it represents the best fit with the reaction order. Table 1 shows the $r^{2}$ and $p$-value of kinetic parameters of PR degradation in storage conditions, like temperature, $\mathrm{pH}$ and light.

The stability results showed that the stability of PR remained constant under conditions of $4 \pm 1$, $30 \pm 1$ and $45 \pm 1^{\circ} \mathrm{C}, \mathrm{pH} 5.5$ and light protection $(p$-value $>0.05)$. In contrast, the regression equation of storage of $\mathrm{PR}$ under $70 \pm 1{ }^{\circ} \mathrm{C}, \mathrm{pH} 2$, $\mathrm{pH} 7.4, \mathrm{pH} 9$ and natural light gave the linear 
A) Thermal stability of $\mathrm{PR}$ at $4^{\circ} \mathrm{C}$

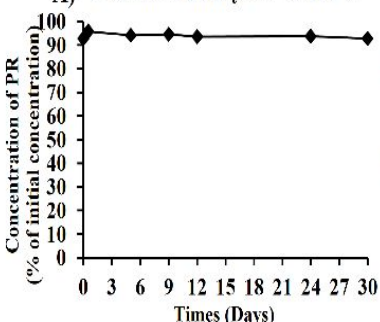

E) $\mathrm{pH}$ stability of $\mathrm{PR}$ at $\mathrm{pH} 2$

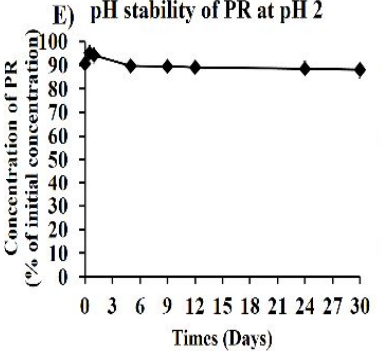

I) Photostability of PR under

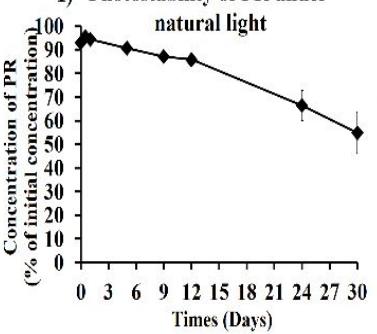

B) Thermal stability of $\mathrm{PR}$ at $30^{\circ} \mathrm{C}$

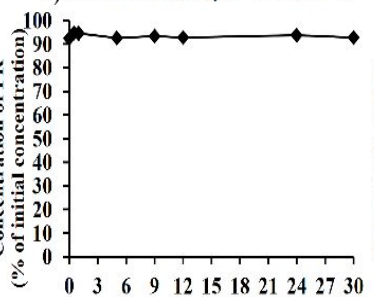

Times (Days)

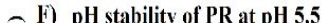

- F) $\mathrm{pH}$ stability of $\mathrm{PR}$ at $\mathrm{pH} 5.5$

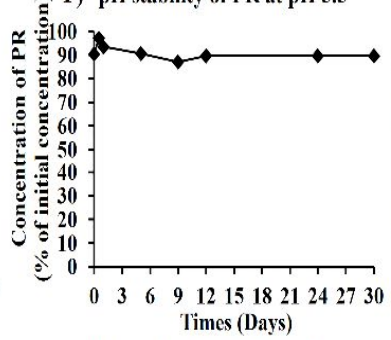

J) Photostability of PR under

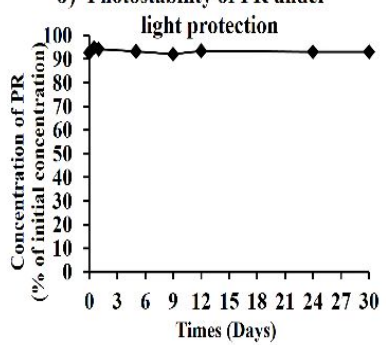

C) Thermal stability of $\mathrm{PR}$ at $45^{\circ} \mathrm{C}$

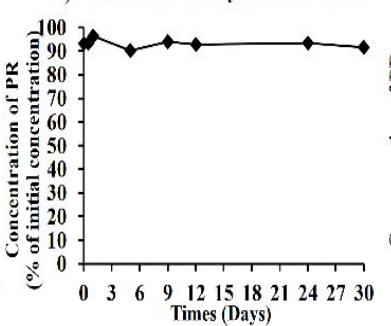

G) $\mathrm{pH}$ stability of $\mathrm{PR}$ at $\mathrm{pH} 7.4$

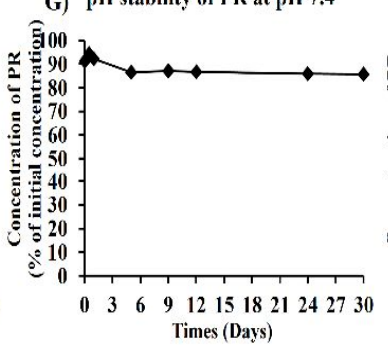

D) Thermal stability of $\mathrm{PR}$ at $70^{\circ} \mathrm{C}$

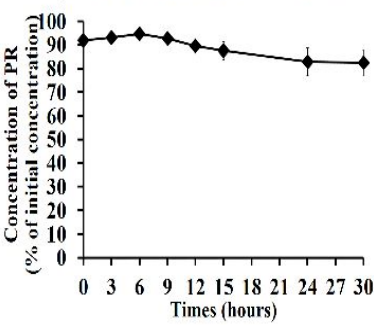

H) $\mathrm{pH}$ stability of $\mathrm{PR}$ at $\mathrm{pH} 9$

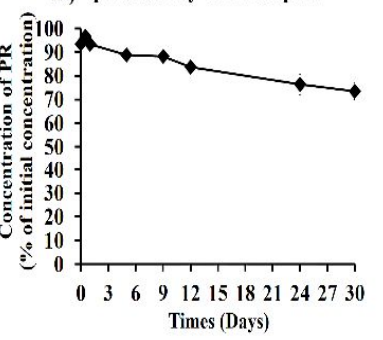

Figure 2: The effect of storage conditions on the PR concentration $(200 \mu \mathrm{g} / \mathrm{ml})$, thermal stability $(A-D), p H$ stability $(E-H)$, and photostability $(I-J)$. Each value represents the mean $\pm \operatorname{SD}(n=3)$

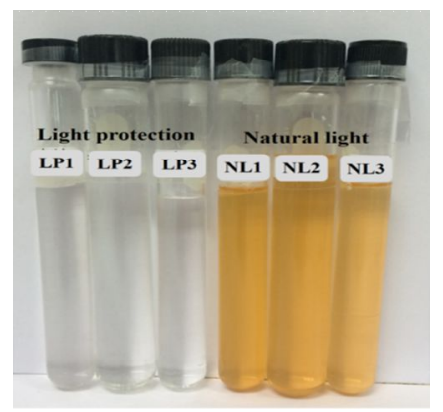

Figure 3: Color of PR solution after stored under light protection (LP1 - LP3) and under natural light (NL1NL2) for 30 days

regression ( $p$-value $<0.05)$. It indicated that there was degradation of PR under these conditions.

The degradation of PR after storing at $70 \pm 1{ }^{\circ} \mathrm{C}$ and $\mathrm{pH} 9$ were fitted to second-order reaction model. The highest $r^{2}$ values were 0.8758 and 0.9816 which were obtained from second-order reaction model under condition at $70 \pm 1{ }^{\circ} \mathrm{C}$ and $\mathrm{pH} 9$, respectively. In case of light conditions, the degradation of PR when it was unprotected under light indicated the zero-order reaction model $\left(r^{2}=0.9671\right)$. Therefore, under natural light, $P R$ in solution form degraded when compared to the initial concentrations. However, the effect of $\mathrm{pH} 2$ and $\mathrm{pH} 7.4$ on PR degradation was not clear in the times of study.

\section{Effect of temperature on vesicular formula- tions containing PR}

The effect of different temperatures on the color change and total active content of PR formulations were evaluated. Figure 4 and Figure 5 showed that the effect of storage conditions on color change and total active content of the ethosomes, transfersomes and invasomes at $4 \pm$ $1,30 \pm 1$ and $45 \pm 1{ }^{\circ} \mathrm{C} / 75 \% \mathrm{RH}$ for 4 months, respectively. The color of PR-ehtosome and transfersome formulations remained unchanged after storing at $4 \pm 1$ and $30 \pm 1{ }^{\circ} \mathrm{C}$ for 4 months (Figure 4), whereas, color change of PRinvasomes was observed after storing for 1 month, and followed by the precipitation of the formulations (Figure 4). This represents the instability of PR-invasomes at $4 \pm 1^{\circ} \mathrm{C}$. However, after increasing temperature of storage to $45 \pm 1^{\circ} \mathrm{C}$, the instability was found in all formulations in 4 months. The color changed to orange, and the precipitation of active ingredient or other formulation were observed (Figure 4). In case of the total active content, all formulations 


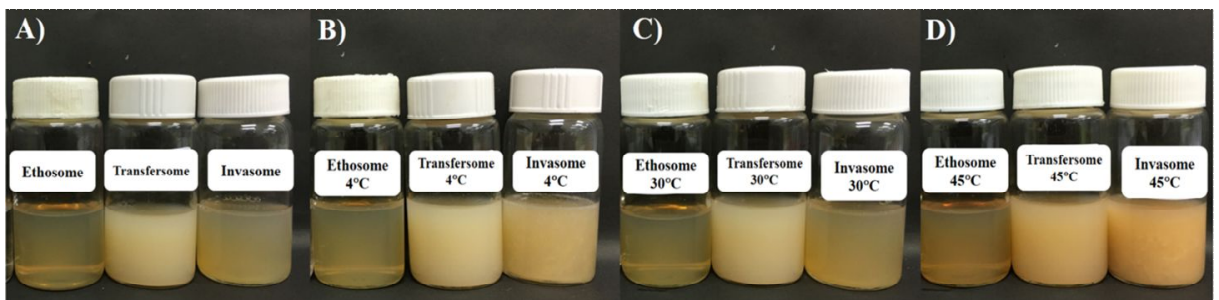

Figure 4: Sedimentation of PR-ethosomes, transfersomes and invasomes before $(A)$ and after storage at $4 \pm 1$ ${ }^{\circ} \mathrm{C},(\mathrm{B}), 30 \pm 1{ }^{\circ} \mathrm{C} / 75 \% \mathrm{RH}(\mathrm{C})$ and $45 \pm 1{ }^{\circ} \mathrm{C} / 75 \% \mathrm{RH}(\mathrm{D})$ for 4 months, respectively
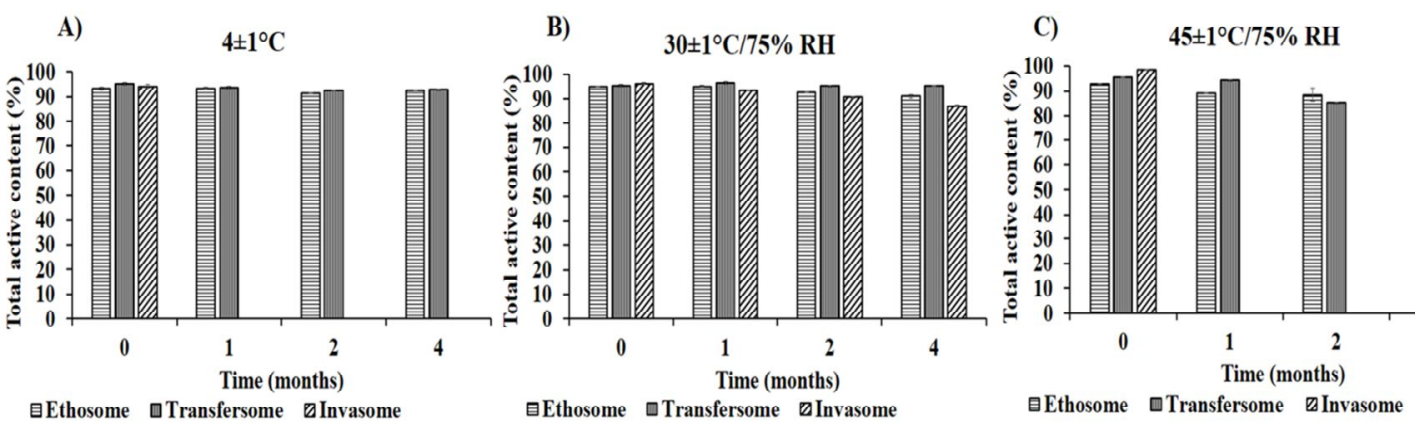

Figure 5: Effect of storage conditions on total active content of the ethosomes, transfersomes and invasomes at $4 \pm 1{ }^{\circ} \mathrm{C}, 30 \pm 1^{\circ} \mathrm{C} / 75 \% \mathrm{RH}$ and $45 \pm 1{ }^{\circ} \mathrm{C} / 75 \% \mathrm{RH}$ for 4 months, respectively

showed that the total active content was approximately $90 \%$ after storing at $30 \pm 1{ }^{\circ} \mathrm{C}$. However, after they were stored at $4 \pm 1{ }^{\circ} \mathrm{C}$ and $45 \pm 1{ }^{\circ} \mathrm{C}$, there were only two systems which were stable, including ethosomes and transfersomes. They had a total active content of more than $90 \%$ over 4 months at $4 \pm 1^{\circ} \mathrm{C}$, and more than $85 \%$ for 2 months at $45 \pm 1^{\circ} \mathrm{C}$. All the results showed that the optimized temperature for storage of these systems was $30 \pm 1{ }^{\circ} \mathrm{C}$.

\section{Effect of natural light on vesicular formula- tion}

In this study, we focus on the effect of natural light on the change of color and total active content of PR. The PR was entrapped within several vesicular formulations, like ethosomes, transfersomes and invasomes. Since the previous study found that after storing the PR solution under natural light at room temperature for 30 days, its color changed from colorless to orange color (Figure 3). In addition, the PR content also decreased about $38.33 \%$ from the initial PR (Figure $2 \mathrm{I}$ ). These results indicated the instability of $P R$ in natural light.

On the other hand, when the PR was entrapped within the ethosome, tranfersome and invasome formulations, it showed that the color of all formulations remained unchanged over 4 months after storage under natural light as shown in Figure $4 \mathrm{C}$. Moreover, the total PR content in the formulation also decreased slightly (Figure 5).

Table 1: Kinetic parameters of PR degradation

\begin{tabular}{|c|c|c|c|c|c|c|c|}
\hline \multirow{3}{*}{\multicolumn{2}{|c|}{ Storage conditions }} & \multicolumn{6}{|c|}{ Kinetic parameter of degradation } \\
\hline & & \multicolumn{2}{|c|}{ Zero-order } & \multicolumn{2}{|c|}{ First-order } & \multicolumn{2}{|c|}{ Second-order } \\
\hline & & P-value & $r^{2}$ & $P$-value & $r^{2}$ & P-value & $r^{2}$ \\
\hline \multirow{4}{*}{$\begin{array}{l}\text { Thermal } \\
\text { stability }\end{array}$} & $4 \pm 1^{\circ} \mathrm{C}$ & 0.1588 & - & 0.1593 & - & 0.1598 & - \\
\hline & $30 \pm 1^{\circ} \mathrm{C}$ & 0.5654 & - & 0.5565 & - & 0.5596 & - \\
\hline & $45 \pm 1^{\circ} \mathrm{C}$ & 0.4222 & - & 0.4272 & - & 0.4324 & - \\
\hline & $70 \pm 1^{\circ} \mathrm{C}$ & 0.0008 & 0.8661 & 0.0007 & 0.8713 & 0.0006 & 0.8758 \\
\hline \multirow{4}{*}{$\begin{array}{l}\mathrm{pH} \\
\text { stability }\end{array}$} & $\mathrm{pH} 2$ & 0.0404 & 0.5307 & 0.0381 & 0.5389 & 0.0359 & 0.5471 \\
\hline & $\mathrm{pH} 5.5$ & 0.2179 & - & 0.2194 & - & 0.2212 & - \\
\hline & $\mathrm{pH} 7.4$ & 0.0308 & 0.5679 & 0.0293 & 0.5747 & 0.0278 & 0.5814 \\
\hline & $\mathrm{pH} 9$ & 0.0000 & 0.9655 & 0.0000 & 0.9749 & 0.0000 & 0.9816 \\
\hline \multirow{2}{*}{$\begin{array}{l}\text { Photo } \\
\text { stability }\end{array}$} & Under light protection & 0.3837 & - & 0.3862 & - & 0.3889 & - \\
\hline & Under natural light & 0.0000 & 0.9671 & 0.0000 & 0.9463 & 0.0002 & 0.9190 \\
\hline
\end{tabular}

Note: Data are mean \pm SEM $(n=5)$ 
shows the effect of storage conditions on total active content of the ethosomes, transfersomes and invasomes at $4 \pm 1{ }^{\circ} \mathrm{C}, 30 \pm 1{ }^{\circ} \mathrm{C} / 75 \% \mathrm{RH}$ and $45 \pm 1{ }^{\circ} \mathrm{C} / 75 \% \mathrm{RH}$ for 4 months, respectively. These results shows that decrement of total PR content at $30 \pm 1{ }^{\circ} \mathrm{C} / 75 \%$ $\mathrm{RH}$ in case of ethosomes, tranfersomes and invasomes were 4.04, 9.12 and $2.50 \%$ of the initial PR, respectively. Figure 6 shows the surface morphology of PR ethosome, transfersome and invasome vesicles when observed by SEM and TEM. SEM photographs indicated spherical structure in all vesicular systems (Figure 6 A - C) while TEM photographs demonstrated unilamellar vesicle structure for invasomes (Figure $6 \mathrm{~F}$ ), and uni- to multi-lamallar vesicle structure for ethosomes (Figure $6 \mathrm{D}$ ) and transfersomes (Figure $6 \mathrm{E}$ ).

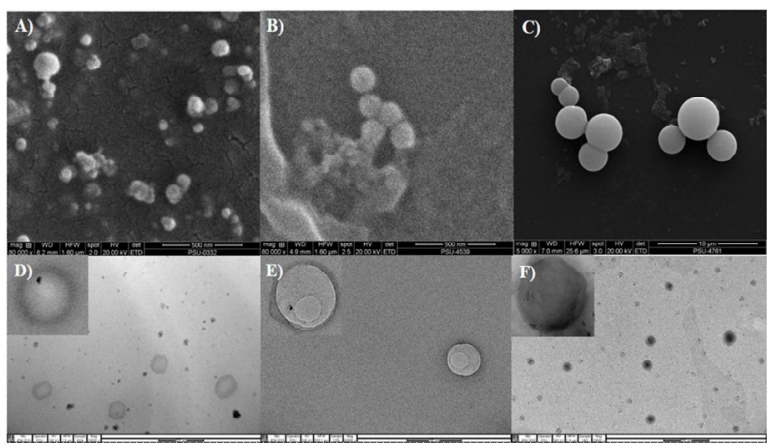

Figure 6: SEM photographs of ethosome (A), transfersome $(B)$ and invasome formulations $(C)$, and TEM photographs of ethosome (D), transfersome (E) and invasome formulations $(F)$, respectively

\section{DISCUSSION}

The solubility property influences formulation and preparation of vesicular formulation. Since PR is hardly soluble in water at all $(265 \mu \mathrm{g} / \mathrm{ml}$ at 25 ${ }^{\circ} \mathrm{C}$ ), the solubility of $\mathrm{PR}$ in various $\mathrm{pH}$ values and ethanol concentrations were studied to discover a suitable dispersion medium for the vesicular formulations. There were no significant differences in the solubility of $\mathrm{PR}$ in various $\mathrm{pH}$ condition and ethanol concentrations between 48 and $72 \mathrm{~h}$, displayed no noticeable differences, which indicated that the solubility of PR had reached equilibrium. The low water solubility of PR may be due to the inability of water, to break into the lattice structure of PR [19]. On the other hand, when the co-solvent systems were used, the PR solubility increased when the ethanol concentration increased. For example, the $10 \%$ ethanol gave the PR solubility of $5.01 \pm 0.04$ $\mathrm{mg} / \mathrm{ml}$ whereas the $50 \%$ ethanol gave the increased PR solubility of $181.44 \pm 1.29 \mathrm{mg} / \mathrm{ml}$ at $25{ }^{\circ} \mathrm{C}$ for $72 \mathrm{~h}$. The solubility enhancement of PR is probably due to the $\mathrm{H}$-bonding interactions of ethanol, because it has both hydrogen bond donor and acceptor properties.

The low stability of PR at very high temperature may be due to the increase in rate of a reaction with increase in temperature. The active ingredient is responsive to degradation at higher temperature through various reactions like hydrolysis, pyrolysis, polymerization, isomerization, rearrangement, and decarboxylation [20]. In fact, light can act as a catalyst to oxidation reactions. Since, PR has low stability in natural light when it is exposed to the light, the color of PR solution changes from colorless to orange or pink tone, which may reduce the effectiveness of PR [5].

The instability of the vesicles may be because of the higher fluidity of lipid bilayers after storing at high temperature. It resulted in higher drug leakage and finally leaded to precipitation of the formulations [15]. In the case of the slight decrease in PR total active content of vesicular formulations, it may be the result of the encapsulation of PR within the vesicles. Therefore, these vesicles could reduce the degradation of PR under natural light, leading to improvement of the physical property, the content of the PR remaining, and the duration of formulation stability. The improvement of PR stability by these vesicles as a result of the encapsulation of PR within the vesicles, which protects the PR from external environment leads to the decrease in degradation reactions, for example hydrolysis and oxidation reactions. In case of transfersomes, the PR was encapsulated at lipid bilayer of the vesicles. In contrast, ethosomes and invasomes which composed of ethanol in the formulation, the PR could be distributed throughout the vesicle [15-17]. The encapsulation of PR within the vesicles helps to protect the PR from the degradation by natural light, resulting in the higher stability for long periods of time.

\section{CONCLUSION}

Formation of vesicles reduces the degradation of PR under thermal and natural light conditions, resulting in the color remaining constant, reduced degradation of PR content, and higher stability.

\section{DECLARATIONS}

\section{Acknowledgement}

We are grateful to the Graduate School, Faculty of Pharmaceutical Sciences and Prince of Songkla University for financial support. Tunyaluk Limsuwan acknowledges the grant of 
the Prince of Songkla University Scholarship for her PhD study.

\section{Conflict of interest}

No conflict of interest is associated with this work.

\section{Contributions of authors}

We declare that this work was done by the authors named in this article and all liabilities pertaining to claims relating to the content of this article will be borne by the authors. The experiments in this study were done by Tunyaluk Limsuwan. Prapaporn Boonme reviewed this manuscript and gave comments for designing this study. Thanaporn Amnuaikit drafted this manuscript and supervised the other authors.

\section{REFERENCES}

1. Linder J. Topical Melasma Treatments. J. Pigment. Disord. 2014; 1(115): 1-3.

2. Chang TS. An updated review of tyrosinase inhibitors. Int. J. Mol. Sci. 2009; 10: 2440-2475.

3. Kott B, Witter C. SymWhite ${ }^{\circledR}$ 377. Symrise AG, 2013 [cited 2015 Nov 19]. Available from: https://products.symrise.com/cosmeticingredients/actives/symwhiter-377/.

4. Romagnoli C, Baldisserotto A, Vicentini CB, Mares $D$, Andreotti $E$, Vertuani $S$, Manfredini $S$. Antidermatophytic Action of Resorcinol Derivatives: Ultrastructural Evidence of the Activity of Phenylethyl Resorcinol against Microsporum gypseum. Molecules. 2016; 21: 2-12.

5. Fan H, Liu G, Huang Y, Li Y, Xia Q. Development of a nanostructured lipid carrier formulation for increasing photo-stability and water solubility of Phenylethyl Resorcinol. Appl. Surf. Sci. 2014; 288: 193-200.

6. Fan $\mathrm{H}, \mathrm{Li}$ Y, Huang Y, Liu G, Xia Q. Preparation and evaluation of phenylethyl resorcinol liposome. Integr. Ferroelectr. 2014; 151: 89-98.

7. Kim BS, Na YG, Choi JH, Kim I, Lee E, Kim SY, Lee JY, Cho CW. The Improvement of Skin Whitening of Phenylethyl Resorcinol by Nanostructured Lipid Carriers. Nanomaterials. 2017; 7(241): 1-17.

8. Verma $P$, Pathak K. Therapeutic and cosmeceutical potential of ethosomes: an overview. J. Adv. Pharm. Technol. Res. 2010; 1(3): 274-282.
9. Zhang $Y T, X u Y M$, Zhang SJ, Zhao JH, Wang Z, $X u D Q$, Feng NP. In vivo microdialysis for the evaluation of transfersomes as a novel transdermal delivery vehicle for cinnamic acid. Drug. Dev. Ind. Pharm. 2014; 40(3): 301-307.

10. Touitou E, Dayan N, Bergelson L, Godin B, Eliaz M. Ethosomes: Novel vesicular carriers for delivery. J. Control. Release. 2000; 65: 403-418.

11. Lakshmi PK, Kalpana B, Prasanthi D. Invasomes-novel vesicular carriers for enhanced skin permeation. Sys. Rev. Pharm. 2013; 4(1): 26-30.

12. The United State of Pharmacopeia 30 and National Formulary 25 (USP30-NF25) Rockville, MD: The U.S. Pharmacopeial Convention, 2007.

13. Ding WJ, Wu XF, Zhong JS, Wan JZ. Effects of temperature, $\mathrm{pH}$ and light on the stability of aloin $A$ and characterisation of its major degradation products. Int. J. Food. Sci. Technol. 2014; 49: 1773-1779.

14. Malesuik MD, Goncalves HML, Paim CS, Schapoval EES, Steppe M. LC: Analysis of Photodegradation Kinetics of Nitazoxanide in Pharmaceutical Formulations. J. Chrom. Sci. 2009; 47: 745-748.

15. Limsuwan $T$, Boonme $P$, Amnuaikit $T$. Effect of Phospholipid and Ethanol Concentrations on Physical Properties and Stability of Phenylethyl Resorcinol Loaded Ethosome. Lat. Am. J. Pharm. 2016; 35(7): 1651-1656.

16. Limsuwan $T$, Boonme $P$, Khongkow $P$, Amnuaikit $T$. Ethosomes of phenylethyl resorcinol as vesicular delivery system for skin lightening applications. BioMed. Research. Int. J. 2017; Article ID 8310979, 12 pages, doi:10.1155/2017/8310979

17. Amnuaikit $T$, Limsuwan $T$, Khongkow $P$, Boonme $P$. Vesicular carriers containing phenylethyl resorcinol for topical delivery system; liposomes, transfersomes and invasomes. Asian J. Pharm. Sci. 2018; 13(5): 472-484.

18. Limsuwan $T$, Boonme $P$, Amnuaikit $T$. The optimized HPLC method for quantitative analysis of phenylethyl resorcinol loaded in the novel vesicle carriers and permeated in in vitro skin permeation study. J. Chrom. Sci. 2017; 55(10): 992-999.

19. Ezealisiji KE, Mbah CJ, Osadebe PO. Aqueous Solubility Enhancement of Mirtazapine: Effect of Cosolvent and Surfactant. Pharmaco. Pharmacy. 2015; 6: 471-476.

20. Rawat T, Pandey IP. Forced degradation studies for Drug Substances and Drug Products- Scientific and Regulatory Considerations. J. Pharm. Sci. Res. 2015; 7(5): 238-241. 